
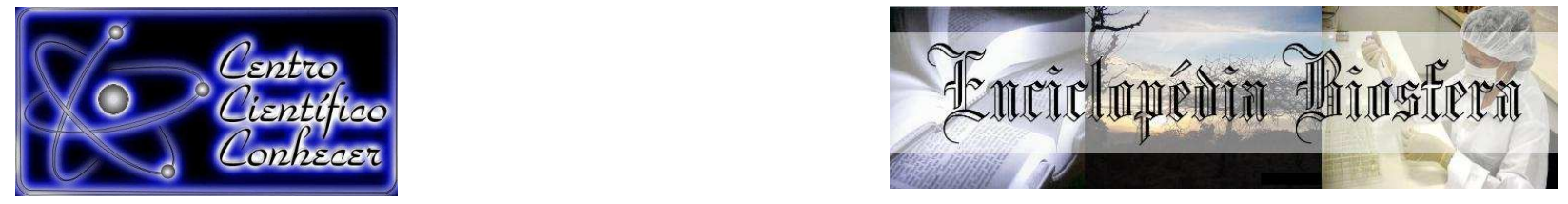

\title{
SUPERAÇÃO DE DORMÊNCIA E USO DE BIOESTIMULANTE NA GERMINAÇÃO DE DIÁSPOROS DE TECA
}

\author{
Patrícia Aparecida de Souza ${ }^{1}$, Thamires Marques Moura ${ }^{2}$, Patrícia Hellenn \\ Stallbaun $^{3}$, Douglas Santos Gonçalves ${ }^{3}$, André Ferreira dos Santos ${ }^{1}$ \\ 1 Professor (a) Dr.(a) do Curso de Engenharia Florestal da Universidade Federal do \\ Tocantins, Gurupi - Brasil (patriciaapsouza@mail.uft.edu.br) \\ 2 Professora Mestra do Instituto Federal Goiano, Iporá - Brasil \\ 3 Mestrando (a) do Programa de Pós Graduação em Ciências Florestais e \\ Ambientais da Universidade Federal do Tocantins, Gurupi - Brasil
}

Recebido em: 03/10/2016 - Aprovado em: 21/11/2016 - Publicado em: 05/12/2016 DOI: 10.18677/EnciBio_2016B_090

\begin{abstract}
Os plantios comerciais de teca (Tectona grandis) vêm aumentando no Brasil e com isso, faz-se necessária a produção de mudas em quantidade e qualidade. Entretanto, a germinação das sementes de teca é lenta e irregular, visto que as estas são inseridas em frutos que apresentam endocarpo e mesocarpos duros e de alta resistência. Este trabalho teve como objetivo avaliar o efeito de diversos tratamentos na superação da dormência dos diásporos de teca. O experimento foi conduzido em delineamento inteiramente casualizado, com 7 tratamentos prégerminativos, com 5 repetições de 6 diásporos cada. O teste de Scott e Knott ao nível de $5 \%$ de probabilidade mostrou o efeito diferencial dos tratamentos na superação de dormência dos diásporos. O tratamento com Booster ${ }^{\circledR}$ em uma concentração de $0,9 \mathrm{~mL}$ mostrou-se o mais eficaz para aumentar a germinação dos diásporos de teca, constituindo uma metodologia nova e eficaz para aumentar a porcentagem de germinação desta espécie.
\end{abstract}

RESUMO

PALAVRAS-CHAVE: Ácido sulfúrico, Booster ${ }^{\circledR}$, dormência, Tectona grandis

\section{OVERCOMING DORMANCY AND BIOSTIMULANT USE IN TECA DIASPORES GERMINATION}

\begin{abstract}
Commercial plantations of teak (Tectona grandis) have been increasing in Brazil and thus, it is necessary to produce seedlings in quantity and quality. However, the germination of teak seeds is slow and irregular, since the seeds are enclosed in fruits that have cored and hard mesocarpos and high strength. This study aimed to evaluate the effect of various treatments to overcome the dormancy of the seeds of teak. The experiment was conducted in a completely randomized design with 7 pregermination treatments with 5 replicates of each 6 diasporas. The Scott and Knott test at $5 \%$ probability showed the differential effect of treatments on breaking dormancy of the seeds. Treatment with Booster ${ }^{\circledR}$ at a concentration of $0.9 \mathrm{~mL}$ proved to be the most effective in increasing the germination of the seeds of teak,
\end{abstract}


constituting a new and effective method to increase the percentage of germination of this specie.

KEYWORDS: Sulfuric acid, Booster ${ }^{\circledR}$, dormancy, Tectona grandis

\section{INTRODUÇÃO}

O Brasil possui cerca de 7,1 milhões de hectares de florestas plantadas, que são responsáveis por abastecer grande parte do mercado brasileiro de madeira. No setor de papel e celulose, a madeira utilizada como matéria-prima tem origem exclusivamente de florestas plantadas (ABRAF, 2013). O interesse brasileiro na teca como espécie alternativa aos plantios florestais tradicionais vem crescendo, podendo ser evidenciado pelo aumento nas áreas com plantio desta espécie (IBÁ, 2015). A área estimada de florestas plantadas com teca no Brasil em 2015 foi de 87.410 ha, enquanto em 2012 essa área era de 67.329 ha (IBÁ, 2016).

A espécie teca (Tectona grandis Linn.F.), pertence à família Lamiaceae, é uma árvore de grande porte e de alta adaptabilidade, nativa das florestas tropicais índicas e asiáticas. No Brasil, é plantada em escala comercial, principalmente, nos estados do Mato Grosso, Amazonas, Acre e Pará. Cultivada desde o século XVIII, quando se destinava principalmente à construção naval, a teca atualmente tem múltiplos fins, tais como na construção civil, na fabricação de assoalhos e decks, sendo também destinada ao setor moveleiro, de embarcações, laminados decorativos e adornos em geral (ABRAF, 2012).

A propagação de teca é realiza via seminal e uma das maiores dificuldades no processo de produção de mudas dessa espécie é a baixa porcentagem de germinação das sementes que ficam dentro de frutos duros e de elevada resistência, ligada a falta de informações sobre a variabilidade genética das sementes disponíveis, além de não existir metodologia de quebra da dormência bem definida (COIMBRA et al., 2014).

A dormência de sementes é fato comum em grande número de espécies florestais. É o fenômeno pelo qual as sementes de uma determinada espécie, mesmo sendo viáveis e tendo todas as condições ambientais favoráveis à germinação, deixam de germinar. Na natureza, é um recurso usado pelas plantas para perpetuação de suas espécies, já que este fenômeno impede que todas as sementes germinem na mesma época, aumentando suas chances de sobrevivência e diminuindo o risco de extinção da espécie (SILVA et al., 2015), podendo variar em função da espécie cultivada, sistema de produção, condições edafoclimáticas, processamento da semente e condições de armazenamento (CARDOSO, et al., 2014).

Entretanto, a dormência das sementes se torna um entrave quando estas são utilizadas para a produção de mudas, em virtude do grande período de tempo necessário para que se iniciem os processos germinativos. No decorrer desse período, as sementes estão sujeitas às condições adversas, com grande possibilidade de ataques de fungos, o que ocasionaria inúmeras perdas (ATAÍDE et al., 2013).

Estudos visando o desenvolvimento de novas metodologias para a quebra de dormência são de grande essencialidade para a aceleração e uniformização do processo germinativo desta espécie, buscando facilitar a etapa de produção de mudas. Segundo RODRIGUES et al., (2015) atualmente existem produtos bioestimulantes que atuam proporcionando melhorias no desempenho das 
sementes, suas respectivas plântulas e até mesmo em estádio mais avançados das culturas.

O bioestimulante origina-se pela mistura de dois ou mais biorreguladores com outras substâncias (aminoácidos, nutrientes, vitaminas), e pode, em função de sua composição, concentração e proporção de substâncias, aumentar o crescimento e desenvolvimento vegetal, instigando a divisão celular, podendo também aumentar a absorção de água e nutrientes pelas plantas (VIEIRA \& CASTRO, 2001).

Diante disto, este trabalho teve como objetivo avaliar o efeito de alguns tratamentos empregados para a superação de dormência de sementes florestais e a aplicabilidade e eficiência do bioestimulante Booster ${ }^{\circledR}$, utilizado para diversas outras culturas, na aceleração da germinação de diásporos de teca.

\section{MATERIAL E MÉTODOS}

O experimento foi conduzido por 30 dias, no período entre os meses de junho e julho de 2013, no laboratório de sementes da Universidade Federal do Tocantins (UFT), Campus Universitário de Gurupi, na região sul do Estado do Tocantins. A altitude da área experimental é $280 \mathrm{~m}$ e as coordenadas são, latitude 1143'45" e longitude 4904'07".

Os diásporos de teca foram fornecidos comercialmente pelo Instituto de Pesquisas e Estudos Florestais - IPEF, do município de Santa Terezinha/Piracicaba - SP. Optou-se por trabalhar com os diásporos de teca, visto que a extração da semente é inviável, uma vez que estas se danificam no momento da quebra do diásporo.

O Booster ${ }^{\circledR}$ é um bioestimulante acelerador de germinação que possui em sua formulação $3 \%$ de cobre, $2 \%$ de molibdênio, $4 \%$ de zinco, $26 \%$ de extrato de algas e outros compostos como esporos de microrganismos, vitaminas, aminoácidos e ácidos húmicos, utilizado até então em espécies agrícolas.

Sua recomendação média de aplicação é de $3 \mathrm{~mL}$ do produto para cada quilo de semente agrícola. Tomando por base a maior necessidade nutricional das espécies florestais e maior área de absorção das sementes, utilizou-se em média de $10 \mathrm{~mL}$ de Booster® para cada quilo de diásporos de teca. Através de pesagens do lote adquirido, obteve-se uma média de 1000 diásporos de teca/kg. Sabendo que cada tratamento constava de 30 diásporos, calculou-se a primeira dosagem do experimento, de $0,3 \mathrm{~mL}$ de concentração. Os tratamentos seguintes foram estabelecidos através da adição de $0,3 \mathrm{~mL}$ do produto de um tratamento para outro, visando encontrar uma concentração ideal para germinação dos diásporos de teca.

Os diásporos foram previamente desinfetados com hipoclorito de sódio (2\%) por quatro minutos e posteriormente lavados com água destilada, conforme descrito por Dias et al., (2009). Os tratamentos utilizados foram: (1) Testemunha - diásporos que não receberam nenhum tipo de tratamento; (2) Imersão dos diásporos em Booster $^{\circledR}$ com concentração de 0,3 mL; (3) Imersão dos diásporos em Booster ${ }^{\circledR}$ com concentração de 0,6 mL; (4) Imersão dos diásporos em Booster ${ }^{\circledR}$ com concentração de 0,9 mL; (5) Imersão dos diásporos em Booster ${ }^{\circledR}$ com concentração de 1,2 mL; (6) Imersão dos diásporos em ácido sulfúrico (33,5\%) por 5 minutos, seguido de lavagem em água destilada; e (7) Imersão dos diásporos em ácido sulfúrico $(33,5 \%)$ por 10 minutos, seguido de lavagem em água destilada.

Após a aplicação dos tratamentos, os diásporos foram distribuídos em papel de germinação umidificados com água destilada (PRADO NETO et al., 2007) e devidamente identificados com seus respectivos tratamentos. Em seguida foram 
colocados e mantidos em câmara de germinação, com temperatura de $30^{\circ} \mathrm{C}$, por um período de 28 dias, conforme recomendação de BRASIL (2009). A reposição de água foi realizada conforme a necessidade.

Devido à ocorrência de 0-4 sementes viáveis por fruto, foram considerados germinados os diásporos que apresentaram, até o vigésimo oitavo dia, pelo menos uma plântula com cotilédones abertos e o primeiro par de folhas. Os resultados foram expressos em percentagem de germinação.

O delineamento utilizado foi inteiramente casualizado, utilizando-se seis diásporos para cada tratamento, com cinco repetições. Os dados foram analisados pelo Programa Estatístico Assistat 7.7 (SILVA, 2016) e submetidos ao teste de médias de Scott e Knott, ao nível de 5\% de probabilidade.

\section{RESULTADOS E DISCUSSÃO}

Conforme observa-se no quadro 1, ocorreu um maior número de germinações quando utilizou-se o tratamento com imersão dos diásporos em Booster $^{\circledR}$, com concentração de $0,9 \mathrm{~mL}$ do produto, onde 23 diásporos germinaram. Em contrapartida, o menor número de germinações foi observado quando se utilizou o tratamento com ácido sulfúrico (33,5\%) por 10 minutos, seguido de lavagem em água destilada, onde nenhum diásporo de teca germinou (Quadro 1).

\begin{tabular}{cccc} 
QUADRO 1 & $\begin{array}{c}\text { Germinação de diásporos de Tectona grandis submetidos a } \\
\text { diferentes tratamentos pré-germinativos. Médias seguidas } \\
\text { da mesma letra não diferem entre si pelo teste de Scott- } \\
\text { Knott a 5\% de probabilidade. }\end{array}$ \\
\hline \multirow{2}{*}{ Trat } & $\begin{array}{c}\text { No sementes } \\
\text { germinadas }\end{array}$ & $\begin{array}{c}\text { Germinação } \\
(\%)\end{array}$ & Médias \\
\hline $\mathbf{1}$ & 4 & 13,33 & $0,80 \mathrm{C}$ \\
$\mathbf{2}$ & 9 & 30,00 & $1,80 \mathrm{~b}$ \\
$\mathbf{3}$ & 11 & 36,67 & $2,20 \mathrm{~b}$ \\
$\mathbf{4}$ & 23 & 76,67 & $4,60 \mathrm{a}$ \\
$\mathbf{5}$ & 10 & 33,33 & $2,00 \mathrm{~b}$ \\
$\mathbf{6}$ & 1 & 3,33 & $0,20 \mathrm{C}$ \\
$\mathbf{7}$ & 0 & 0,00 & $0,00 \mathrm{C}$ \\
C.V. (\%) & -- & -- & 56,94 \\
\hline
\end{tabular}

O desempenho dos tratamentos com ácido sulfúrico ( 6 e 7) não diferiram do tratamento testemunha (1) pelo teste de Scott-Knott ao nível de $5 \%$ de probabilidade, quadro 1. Tal fato demonstra que a utilização de ácido sulfúrico pode ser prejudicial para a germinação de teca, uma vez que os diásporos que não receberam nenhum tipo de tratamento apresentaram maior taxa de germinação que os diásporos tratados com o ácido sulfúrico. Estudo realizado com Schinopsis brasiliensis por ALVES et al., (2007) ratificam as informações encontradas, onde a utilização de ácido sulfúrico por 3 minutos interferiu drasticamente na germinação, causando a morte de quase todas as sementes. Em contrapartida, COSTA et al., (2010) trabalhando com Adenanthera pavonina obtiveram resultados diferentes, já que a imersão das sementes em ácido sulfúrico, por 5 e 10 minutos, foi mais favorável à superação da dormência, em relação aos demais tratamentos.

COIMBRA et al., (2014) observaram que os diásporos de teca que passaram pela escarificação química com utilização de ácido sulfúrico apresentaram uma 
redução significativa na sua taxa de germinação, por provável danificação do embrião das sementes. Além de baixas taxas de germinação e o maior risco na manipulação do ácido sulfúrico, desestimulam a utilização da escarificação ácida para a quebra de dormência em teca.

Verificou-se que os tratamentos 2, 3 e 5, realizados com aplicação de Booster $^{\circledR}$ em diferentes concentrações, não apresentaram diferença significativa entre si. Entretanto, houve diferença significativa entre estes tratamentos e a testemunha, onde a porcentagem de germinação dos diásporos foi maior nos tratamentos com o uso do bioestimulante. O tratamento 4, que utilizou a imersão dos diásporos em Booster ${ }^{\circledR}$ com concentração de $0,9 \mathrm{~mL}$, diferiu estatisticamente de todos os outros tratamentos, apresentando maior porcentagem de germinação (76,67\%) (Quadro 1).

De acordo com VIEIRA \& CASTRO (2001), os bioreguladores vegetais são substâncias sintetizadas que, aplicadas exogenamente, possuem ações similares aos grupos de hormônios vegetais conhecidos como as citocininas, giberelinas, auxinas e etileno. Esses produtos agem na degradação de substâncias de reserva das sementes, na diferenciação, divisão e alongamento celulares.

Estudo realizado por PRADO NETO et al., (2007) corrobora com os resultados encontrados no presente trabalho, onde uma menor dose de bioestimulante Stimulate ${ }^{\circledR}$ não apresentou efeito significativo sobre a germinação de sementes, no entanto, observaram resultados positivamente significativos quando pré-embeberam sementes de jenipapo (Genipa americana L.) em dose maior de bioestimulante Stimulate ${ }^{\circledR}$, proporcionando maiores índices de velocidade de germinação em relação aos demais tratamentos, indicando efeito positivo do bioestimulante na melhoria do desempenho das sementes, dependendo da dosagem utilizada.

Em trabalho com faveiro (Dimorphandra mollis), CANESIN et al., (2012) verificaram que o Stimulate ${ }^{\circledR}$ influenciou positivamente o desempenho das sementes e o crescimento inicial da espécie, aumentando a porcentagem e a velocidade de emergência de plântulas.

Os resultados encontrados no presente estudo divergem dos resultados obtidos por PIEREZAN et al., (2012), onde as doses utilizadas de Stimulate ${ }^{\circledR}$ ocasionaram a inibição da germinação e do crescimento de jatobá (Hymenaea courbaril L.), sendo que a germinação das sementes foi maior quando não se utilizou o bioestimulante.

A aplicação de bioestimulantes em culturas agrícolas já é conhecida, a exemplo dos estudos realizados por FERREIRA et al., (2007) onde a aplicação do Stimulate ${ }^{\circledR}$ nas concentrações de 12 e $16 \mathrm{~mL}$ do bioestimulante por quilograma de semente promoveu maiores porcentagens de emergência e desenvolvimento de plântulas de maracujá ( $P$. edulis) e por SILVA et al., (2008), onde a aplicação dos bioestimulantes Cellerate ${ }^{\circledR}$ e Booster ${ }^{\circledR}$ nas sementes híbridas de milho GNZ 2004 proporcionaram um aumento nos valores de germinação quando comparadas aos observados na testemunha. Entretanto, o conhecimento e sua utilização como acelerador de germinação em sementes de espécies florestais ainda é incipiente.

\section{CONCLUSÕES}

O tratamento com Booster ${ }^{\circledR}$ em uma concentração de $0,9 \mathrm{~mL}$ mostrou-se o mais eficaz para aumentar a germinação dos diásporos de teca, constituindo assim, 
uma metodologia nova e eficaz para aumentar a porcentagem de germinação desta espécie.

Em contrapartida, o tratamento dos diásporos de teca com ácido sulfúrico não são recomendados para a superação de dormência, pois não elevaram o potencial germinativo da espécie.

\section{REFERÊNCIAS}

ABRAF. Anuário estatístico da ABRAF 2013 ano base 2012. Brasília: ABRAF, 2013. $142 \mathrm{p}$.

ABRAF. Anuário estatístico da ABRAF 2012 ano base 2011. Brasília: ABRAF, 2012. 150 p.

ALVES, A. F.; ALVES, A. F.; GUERRA, M. E. de C.; MEDEIROS FILHO, S. Superação de dormência de sementes de braúna (Schinopsis brasiliense Engl.). Ciência Agronômica, v. 38, n. 1, p. 74-77, 2007. Disponível em: < http://ccarevista.ufc.br/seer/index.php/ccarevista/article/view/154/148>.

ATAÍDE, G. da. M.; BICALHO, E. M.; DIAS, D. C. dos. S.; CASTRO, R. V. O.; ALVARENGA, E. M. Superação da dormência das sementes de Delonix regia (Bojer ex Hook.) Raf. Revista Árvore, v. 37, n. 6, pp.1145-1152, 2013. doi: <http://dx.doi.org/10.1590/S0100-67622013000600016>.

BRASIL. Ministério da Agricultura, Pecuária e Abastecimento. Regras para análise de sementes. Brasília: Mapa/ACS, 2009. 399p.

CANESIN, A.; MARTINS, J. M. D. T.; SCALON, S. de P. Q.; MASETTO, T. E. Bioestimulante no vigor de sementes e plântulas de faveiro (Dimorphandra mollis Benth.). Cerne, v. 18, n. 2, p. 309-315, 2012. Disponível em: < http://dx.doi.org/10.1590/S0104-77602012000200016>. doi: 10.1590/S010477602012000200016.

CARDOSO, E. D.; SÁ, M. E.; HAGA, K. I.; BINOTTI, F. F.S.; NOGUEIRA, D. C.; VALÉRIO FILHO, W. V. Desempenho fisiológico e superação de dormência em sementes de Brachiaria brizantha submetidas a tratamento químico e envelhecimento artificial. Semina: Ciências Agrárias, v. 35, n. 1, p. 21-38, 2014. doi: 10.5433/1679-0359.2014v35n1p21.

COIMBRA, E. C.; VAZQUEZ, G. H.; NOGUEIRA, T. O. Superação da dormência e o uso de fungicida em diásporos de teca. Rev. bras. eng. agríc. Ambiente, v.18, n.12, p.1281-1286, 2014. doi: 10.1590/1807-1929/agriambi.v18n12p1281-1286.

COSTA, P. A.; LIMA, A. L. da S.; ZANELLA, F.; FREITAS, H. de. Quebra de dormência em sementes de Adenanthera pavonina L. Pesquisa Agropecuária Tropical, v. 40, n. 1, p. 83-88, 2010. Disponível em: < http://revistas.ufg.emnuvens.com.br/pat/article/view/4092>. doi: 10.5216/pat.v40i1.4092 
DIAS, J. R. M.; CAPRONI, A. L.; WADT, P. G. S.; SILVA, L. M. da; TAVELLA, L. B.; OLIVEIRA, J. P. de. Quebra de dormência em diásporos de teca (Tectona grandis L.f.). Acta Amazonica, v. 39, n. 3, p. 549-554, 2009. Disponível em: < http://dx.doi.org/10.1590/S0044-59672009000300009>. doi: 10.1590/S004459672009000300009

FERREIRA, G.; COSTA, P. N.; FERRARI, T. B.; RODRIGUES, J. D.; BRAGA, J. F.; JESUS, F. A. Emergência e desenvolvimento de plântulas de maracujazeiro azedo oriundas de sementes tratadas com bioestimulante. Revista Brasileira de Fruticultura, v. 29, n. 3, p. 595-599, 2007. Disponível: <http://dx.doi.org/10.1590/S0100-29452007000300034>. doi: 10.1590/S010029452007000300034.

INDÚSTRIA BRASILEIRA DE ÁRVORES - IBÁ. Anuário estatístico 2015: ano base 2014. Brasília, 2015. 80 p. Disponível em: <http://iba.org/images/shared/iba_2015.pdf>.

INDÚSTRIA BRASILEIRA DE ÁRVORES - IBÁ. Anuário estatístico 2016: ano base 2015. Brasília, 2016. 100 p. Disponível em: <http://iba.org/images/shared/Biblioteca/IBA_RelatorioAnual2016_.pdf>.

PIEREZAN, L.; SCALON, S. de P. Q.; PEREIRA, Z. V. Emergência de plântulas e crescimento de mudas de jatobá com o uso de bioestimulante e sombreamento. Cerne, v. 18, n. 1, p. 127-133, 2012. Disponível em: < http://dx.doi.org/10.1590/S0104-77602012000100015>. doi: 10.1590/S010477602012000100015

PRADO NETO, M.; DANTAS, A. C. V. L.; VIEIRA, E. L.; ALMEIDA, V. de O. Germinação de sementes de jenipapeiro submetidas à pré-embebição em regulador e estimulante vegetal. Ciência e Agrotecnologia, v. 31, n. 3, p. 693-698, 2007. Disponível em: < http://www.scielo.br/pdf/cagro/v31n3/a14v31n3>.

RODRIGUES, L. A.; BATISTA, M. S.; ALVAREZ, R. C. F.; LIMA, S. F., ALVES, C. Z. Avaliação fisiológica de sementes de arroz submetidas a doses de bioestimulante. Nucleus, Ituverava, v. 12, n. 1, p.207-214, 2015. doi: 10.3738/1982.2278.1376.

SILVA, D. G.; BATISTA, D. A.; FONSECA, M. C.; PEREIRA, M. de. Q.; FERREIRA, V. H.; MACHADO, V. de. M. Quebra de dormência das sementes de "guapuruvu" (Schizolobium parahyba) na região de Patos de Minas - MG. Revista Cenar, v. 1, n. 1, p.1-4, 2015. Disponível em: <http://revistas.unipam.edu.br/index.php/cenar/article/view/130/72>.

SILVA, F. de. A. S., 2016. ASSISTAT: Versão 7.7 beta. DEAG-CTRN-UFCG Atualizado em 01 de março de 2016. Disponível em <http://www.assistat.com/>. Acesso em: 17 de jun. de 2016.

SILVA, T. T. D. A.; PINHO, E. V. de R. V.; CARDOSO, D. L.; FERREIRA, C. A.; ALVIM, P. de O. A.; COSTA, A. A. F. da. Qualidade fisiológica de sementes de milho na presença de bioestimulantes. Ciência e Agrotecnologia, v. 32, n. 3, p. 840-846, 
2008. Disponível: < http://dx.doi.org/10.1590/S1413-70542008000300021>. doi: 10.1590/S1413-70542008000300021.

VIEIRA, E. L.; CASTRO, P. R. C. Ação de bioestimulante na germinação de sementes, vigor de plântulas, crescimento radicular e produtividade de soja. Revista Brasileira de Sementes, v. 23, n. 2, p. 169-174, 2001. 